\title{
Enthalpies of Solution of the Nucleic Acid Bases. 3. Cytosine in Water
}

\author{
Marthada V. Kilday \\ Center for Thermodynamics and Molecular Science, National Bureau of Standards, Washington, D.C. 20234
}

June 19, 1978

An adiabatic solution calorimeter was used for measuring enthalpies of solution in water of seven samples of cytosine for which analytical data are given.

Our best values are:

$$
\Delta H^{\circ}(\infty, 298.15 \mathrm{~K})=(27.2 \pm 4.0) \mathrm{kJ} \cdot \mathrm{mol}^{-1},
$$

and

$$
\Delta C_{p}=(76 \pm 21) \mathrm{J} \cdot \mathrm{mol}^{-1} \cdot \mathrm{K}^{-1}, 298 \mathrm{~K}<\mathrm{T}<324 \mathrm{~K} \text { at }(24 \pm 2) \mathrm{mmol} \cdot \mathrm{kg}^{-1} .
$$

Evidence is given for an unidentified side reaction at low concentrations which is responsible for the large uncertainty assigned to the enthalpy of solution at infinite dilution. An approximate value of $(1.44 \pm 0.08) \mathrm{g} \cdot \mathrm{mL}^{-1}$ for the density of cytosine was also measured. Values are calculated for $\Delta G^{\circ}$ and $\Delta S^{\circ}$ for the solution reaction.

Key Words: 4-amino-2 (1H)-pyrimidinone; calorimetry; cytosine: density, enthalpy of solution, entropy of solution; nucleic acid bases; thermochemistry.

\section{Introduction}

This is the third in a series of papers $[1,2]^{1}$ describing the measurements of enthalpies of solution of the bases of the nucleic acids with emphasis on the characterization of the samples as an aid in establishing uncertainty limits for the measured values. The first paper in this series described in detail the general procedures which were also followed in this work.

Enthalpy of solution measurements are reported here for four samples of cytosine from commercial sources as received and for three samples which were further purified by sublimation and by recrystallization from water and from ethyl alcohol solutions. Measurements were made in the temperature range 298 to $329 \mathrm{~K}$ and in the concentration range 2 to $35 \mathrm{mmol} \cdot \mathrm{kg}^{-1}$.

\footnotetext{
${ }^{1}$ Figures in brackets indicate the literature references at the end of this paper.
}

Cytosine, a pyrimidine base, is slightly soluble in water at $298 \mathrm{~K}\left(8.5 \mathrm{~g} \cdot \mathrm{L}^{-1}[3]\right)^{2}$, and sublimes and decomposes before melting. It has the following structural formula [5]:<smiles>Nc1cc[nH]c(=O)n1</smiles>

Only one measured value for the enthalpy of solution of cytosine in water has been reported previously [6]. This was a small part of a study of heat transfer coefficients and was not intended as a measurement of high accuracy.

${ }^{2}$ The National Bureau of Standards (U.S.) has recently recommended the use of "L" as the symbol for liter, the metric unit commonly used to measure volume [4]. 


\section{The Cytosine (Cyt) Samples}

The following information about the cytosine samples from commercial sources $^{3}$ was obtained primarily from labels, catalogs, or brochures supplied by the manufacturer or distributor:

Cyt 1. Calbiochem, Cat. No. 2510, Lot 840095, 25 g, Grade A received about 1970 - exact date unknown. (Listed as "hemihydrate" in the catalog; elemental analysis indicated it was anhydrous.) Analysis: Nitrogen, $37.60 \%$; Spectra at pH 1: 250/260 0.46, 280/260 1.52, 290/260 0.77, $\lambda \max 275 \mathrm{~m} \mu, \epsilon \max 10,200, \lambda \min 238 \mathrm{~m} \mu, \epsilon \min 1,000$; Chromat. Homogeneous

Cyt 2. E-M Laboratories, Cat. No. 2326, Lot 1958515 (sic), 5 g received June 1974. Listed as "Cytosine for Biochemistry." Type analysis: Optical properties, measured values at $\mathrm{pH} l$ (sic): $\lambda \max 275, \mathrm{E}_{\mathbf{2 5 0}} / \mathrm{E}_{\mathbf{2 6 0}} 0.48$ $\pm 0.02, \mathrm{E}_{280} / \mathrm{E}_{260} 1.50 \pm 0.03, \mathrm{E}_{290} / \mathrm{E}_{260} 0.77 \pm 0.02$. Thin Layer Chromatography: Layer TLC plates PEI-Cellulose F, pre-coated, Solvent Saturated ammonium sulfate solution/1 M sodium acetate solution/2-propanol $(80 / 18 / 2) . R_{f}$ value: $\sim 0.65$

Cyt 3. Same as Cyt 2 except $55 \mathrm{~g}$ of Lot 4955544 received August 1974 .

Cyt 4. Same as Cyt 2 except 5 g of Lot 4958785 received January 1975.

These samples were all finely divided white powders and there was no visible difference in their appearance. The enthalpy of solution measurements were made on the samples as received or after vacuum drying.

The following samples were purified from Cyt 3 in this laboratory:

Cyt 3a and $\mathbf{b}$ were twice recrystallized as described for Thy $3 a$ and $b$ [2]. For Cyt $3 \mathrm{a}, 20 \mathrm{~g}$ was dissolved in $0.25 \mathrm{~L}$ of boiling distilled $\mathrm{H}_{2} \mathrm{O}$ with activated charcoal as a decolorizer; it was then filtered and slowly cooled. The yield from a second crystallization was $6.9 \mathrm{~g}$. For Cyt $3 \mathrm{~b}, 10 \mathrm{~g}$ was dissolved in $0.5 \mathrm{~L}$ of boiling 90 percent ethyl alcohol, activated charcoal was added, the solution was filtered and slowly cooled. The yield from a second crystallization was $7.9 \mathrm{~g}$.

Cyt 3d. This was the product of vacuum-sublimation as described [1] for Ade $1 c$ and $5 c$ except that the maximum temperature here was about 475 K. The sublimation was stopped after 4 days although only about one-half of the $5 \mathrm{~g}$ sample had sublimed. The product was removed from the sublimation vessel in a glove box containing an $\mathrm{H}_{2} \mathrm{O}$ absorber, and all subsequent manipulations of this sublimate were performed in the glove box.

Cyt 3e. This was the unsublimed residue from sublimation of Cyt 3d. The residue had a brown discoloration of the portion in contact with the glass vessel which was evidence of apparent decomposition.

\subsection{Characterization of the Samples}

The purity of cytosine could not be determined from melting-temperature measurements because it decomposes before melting. Therefore, it was necessary to search for impurities and to characterize as completely as possible the

\footnotetext{
${ }^{3}$ The information presented in this paper is in no way intended as an endorsement nor a condemnation of any of the materials or services used. Commercial sources are named only for specific identification.
}

samples on which enthalpies of solution were measured as an aid in the assignment of uncertainty limits for the measured values.

In this laboratory densities were determined by displacement, volatile matter by vacuum drying, $\mathrm{H}_{2} \mathrm{O}$ by Karl Fischer titrations, and other impurities by paper and thin layer chromatography (TLC). Other laboratories contributed analyses of the elemental compositions, emission spectra, $\mathrm{x}$-ray diffraction patterns, and the measurement of the heat capacity of the crystalline cytosine.

\subsubsection{Density, Volatile Matter, and $\mathrm{H}_{2} \mathrm{O}$}

The densities of two of the cytosine samples were measured by a benzene displacement method; details of the method have been described [1]. Duplicate density measurements were: for Cyt $1,1.475$ and $1.491 \mathrm{~g} \cdot \mathrm{mL}^{-1}$, and for Cyt 3, 1.418 and $1.388 \mathrm{~g} \cdot \mathrm{mL}^{-1}$. The mean value of $(1.44 \pm 0.08)$ $\mathrm{g} \cdot \mathrm{mL}^{-1}$ was used in calculating the buoyancy factor, 1.0007 , for the cytosine mass corrections in this work.

The volatility and hygroscopicity of the cytosine samples were determined from changes in mass after vacuum-drying (see [1] for details) and exposure to atmospheric moisture ( $\sim 35 \%$ relative humidity). The samples, contained in aluminum moisture dishes, were vacuum-dried 4 hours and weighed, then dried again for 2-h intervals and weighed, until the total drying time was 10 to 14 hours. At $340 \mathrm{~K}$, samples of Cyt 1 (1, 2, and $3 \mathrm{~g})$ had reached constant mass after $4 \mathrm{~h}$ with a loss of $0.5 \mathrm{mg} \cdot \mathrm{g}^{-1}$. The 3 -g sample was then exposed to the atmosphere before drying at $375 \mathrm{~K}$ along with 3-g samples of Cyt 2, 3, and 4; the losses were 1.6, 2.9, 2.8 , and $4.4 \mathrm{mg} \cdot \mathrm{g}^{-1}$, respectively, and they were at constant mass after about 6 hours of drying. This sample of Cyt 4 was exposed to the atmosphere for 64 hours and gained 1.2 $\mathrm{mg} \cdot \mathrm{g}^{-1}$, but there was no further gain in mass after an additional 30 hours exposure to the atmosphere. This agrees with the findings of Falk [7] that cytosine does not form hydrates even at 93 percent relative humidity. When this sample was vacuum dried for 2 hours at $375 \mathrm{~K}$, it again returned to the same constant mass as before. Again exposure to the atmosphere resulted in the following gains in mass in $\mathrm{mg} \cdot \mathrm{g}^{-1}: 0.1$ after $1 \mathrm{~min}, 0.6$ after $10 \mathrm{~min}, 0.9$ after $25 \mathrm{~min}$, 1.0 after $40 \mathrm{~min}$, and 1.2 after 18 hours; thus, one-half of the mass increase occurred during the first $10 \mathrm{~min}$ and the mass at equilibrium with the atmosphere was reproduced. This sample was then included in observations of mass changes after relatively long periods of vacuum drying at 375 K; samples of Cyt $3 \mathrm{a}$ and b and Thy 2 and 4 [2] were heated simultaneously. Cyt $3 \mathrm{a}$ and $\mathrm{b}$ had previously been dried at $340 \mathrm{~K}$ at atmospheric pressure and reached constant mass. After 24 hours of vacuum drying at $375 \mathrm{~K}$, they each lost about $0.7 \mathrm{mg} \cdot \mathrm{g}^{-1}$; and the masses remained essentially constant for an additional 110 hours of drying. As previously 
reported [2], Thy 2 and 4 were losing mass at the rate of 600 and $100 \mu \mathrm{g} \cdot \mathrm{g}^{-1} \cdot \mathrm{h}^{-1}$, respectively. The sample of Cyt 4 which had proven stable during the vacuum heating lost only about $0.1 \mathrm{mg} \cdot \mathrm{g}^{-1}$ during 30 hours of continuous vacuum heating, but then surprisingly began to gain mass: 1.6 $\mathrm{mg} \cdot \mathrm{g}^{-1}$ after 22 hours, and additional $1.3 \mathrm{mg} \cdot \mathrm{g}^{-1}$ after the next 22 hours, and finally a gain of about $4.5 \mathrm{mg} \cdot \mathrm{g}^{-1}$ after a total of 130 hours. When the two thymine samples were removed from the oven, the gain in mass of Cyt 4 ceased. It is assumed that the thymine samples were subliming onto this cytosine sample. However, it is not understood why it was apparently selective; Cyt $3 \mathrm{a}$ and $\mathrm{b}$ were in cylindrical glass weighing bottles while the Cyt 4 , Thy 2, and Thy 4 were in aluminum moisture dishes, and only the Cyt 4 sample showed the gain in mass.

From these observations it is concluded that cytosine is essentially non-hygroscopic and that the volatile matter, presumed to be $\mathrm{H}_{2} \mathrm{O}$, is (in mass \%): Cyt 1, 0.16; Cyt 2, 0.29; Cyt 3, 0.28; and Cyt 4, 0.44.

Karl Fischer titrations for $\mathrm{H}_{2} \mathrm{O}$ in Cyt 1, 2, 3, and 4, indicated $0.26,0.31,0.33$, and 0.43 mass percent, respectively. (See [2] for details of the procedure.) The cytosine samples dissolved completely in the methanol solvent, and the values represent the total $\mathrm{H}_{2} \mathrm{O}$ in the samples. These results are in good agreement with those obtained for volatile matter. Corrections to the calorimetric data for $\mathrm{H}_{2} \mathrm{O}$ in the sample use the mean of the titration results and the volatile matter measurements, namely, 0.21 mass percent for Cyt 1; 0.30 , for Cyt 2; 0.30, for Cyt 3; and 0.44, for Cyt 4. The other samples had been vacuum dried and required no corrections for $\mathrm{H}_{2} \mathrm{O}$.

\subsubsection{Other Analyses}

The emission spectra for Cyt $1,2,3$, and $4^{4}$ showed no impurities beyond the background limits listed for adenine [1].

The results of duplicate elemental analyses of Cyt 1, 3, and $3 \mathrm{a}$ are given in table 1 . Within the estimated accuracy of 0.2 percent for each determination, the analyses for all three samples correspond to the composition of anhydrous cytosine, except the $\mathrm{C}$ and $\mathrm{O}$ in Cyt $\mathrm{l}$ and the $\mathrm{O}$ for Cyt 3 which are a little high, and the $\mathrm{N}$ for Cyt 3 which is a little low. However, none of the analytical values are close to the theoretical composition of the hemihydrate (the catalog for Cyt 1 had listed the material as the hemihydrate). Since the samples are anhydrous, no significant error in the enthalpy of solution can be attributed to the presence of hydrates of cytosine.

Stirred solutions of Cyt 1 and of Cyt $3\left(15 \mathrm{mmol} \cdot \mathrm{kg}^{-1}\right)$ in equilibrium with air (as in the calorimetric solutions) were at $\mathrm{pH} 6.4 \pm 0.1$. The $\mathrm{pH}$ meter was calibrated with a standard

${ }^{4}$ Analyses by J. A. Norris, Center for Analytical Chemistry, National Measurement Laboratory, National Bureau of Standards.

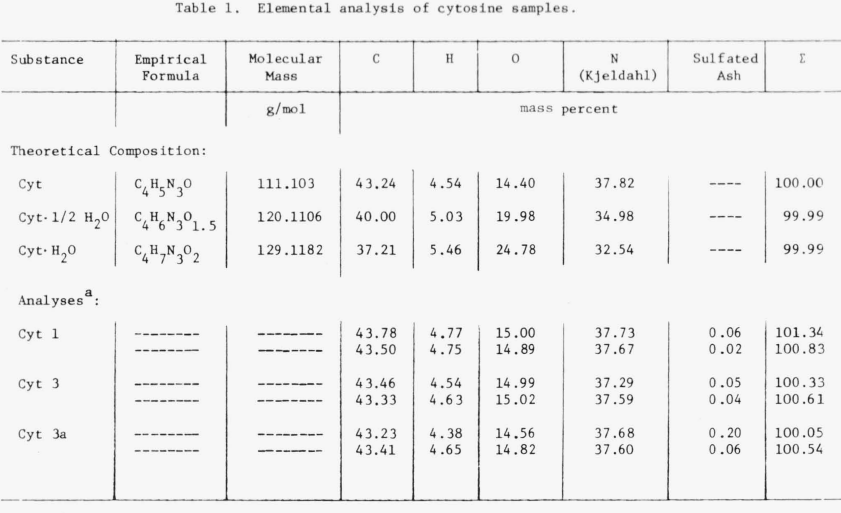

a The analyses by Micro-Analysis, Inc., W11mington DE, have an estimated accuracy

buffer at $\mathrm{pH} 7.00$ and checked at the end of the measurements.

The procedures followed in our paper and thin-layer (TLC) chromatography work and the observations regarding backgrounds and sensitivity have been previously discussed in detail [1]. $R_{f}$ values obtained for the four commercial cytosine samples as received are compared in table 2 with those reported in the National Academy of Sciences (NAS) publication [8]. Our values have in general tended to be somewhat higher than those of NAS; this is probably due to differences in laboratory temperature or other experimental conditions.

The estimated uncertainty in reading the chromatograms is $\pm 0.02 R_{f}$ unit. Within this uncertainty, the cytosine samples listed in table 2 showed no significant differences in any of the solutions and no spots other than that of the major component were visible. Therefore, it is concluded that the four cytosine samples are of equal purity (probably $95 \%$ or more) within the limits of chromatographic detection.

\subsubsection{Calorimetric Characterization}

The heat capacities at $298 \mathrm{~K}$ of two of our crystalline samples were measured by Ernesto Friere using a drop microcalorimeter at the University of Virginia. His values were reported as $(1.197 \pm 0.004) \mathrm{J} \cdot \mathrm{g}^{-1} \cdot \mathrm{K}^{-1}$ for Cyt 1 and $(1.188 \pm 0.004) \mathrm{J} \cdot \mathrm{g}^{-1} \cdot \mathrm{K}^{-1}$ for Cyt 3 [9]. The mean value is $C_{p}^{\circ}=(132.5 \pm 0.8) \mathrm{J} \cdot \mathrm{mol}^{-1} \cdot \mathrm{K}^{-1}$.

\section{Enthalpies of Solution}

The enthalpies of solution in $\mathrm{H}_{2} \mathrm{O}$ of four commercial samples of cytosine as received and products of recrystallization and of sublimation were measured in the platinumlined adiabatic solution calorimeter which has been previously described in detail $[10,11]$. The solution volume was approximately $300 \mathrm{~mL}$ and the capacity of the platinum sample holder [10] was 0.7 or $3.0 \mathrm{~mL}$ depending on which of two interchangeable cylinders was used. Measurements were 
Table 2. $\mathrm{R}_{\mathrm{f}}$ values for the cytosine samples in $\mathrm{NH}_{4} \mathrm{OH}$ (aq, 1 o $1 \cdot \mathrm{L}^{-1}$ ) solutions on fluorescent TLC plates and two
papers with four carrier solutions, $\mathrm{A}, \mathrm{B}, \mathrm{C}$, and $\mathrm{D}$.

\begin{tabular}{|c|c|c|c|c|c|c|c|c|c|c|c|c|}
\hline \multirow{2}{*}{$\begin{array}{l}\text { Cytosine } \\
\text { Sample No. }\end{array}$} & \multicolumn{3}{|c|}{$A^{B}$} & \multicolumn{3}{|c|}{$\mathrm{B}^{\mathrm{a}}$} & \multicolumn{3}{|c|}{$c^{\mathrm{a}}$} & \multicolumn{3}{|c|}{$D^{a}$} \\
\hline & TLC & $\mathrm{P}-1$ & $P-40$ & TLC & P-1 & $P-40$ & TLC & P-1 & $P-40$ & TLC & $\mathrm{P}-1$ & $P-40$ \\
\hline 1 & 0.79 & 0.78 & 0.84 & 0.56 & 0.58 & 0.60 & 0.60 & 0.71 & -- & 0.83 & 0.76 & 0.73 \\
\hline 2 & .79 & .78 & .83 & .58 & .56 & .60 & .60 & .70 & $-\cdots$ & .82 & .74 & .69 \\
\hline 3 & .79 & .78 & .82 & .56 & .56 & .60 & .60 & .70 & |--- & .82 & .73 & .71 \\
\hline 4 & .80 & .78 & .82 & .54 & .56 & .60 & .60 & .70 & - & .84 & .74 & .72 \\
\hline NAS [8] & & & 0.76 & & & 0.50 & & & 0.70 & & & 0.71 \\
\hline
\end{tabular}

The composition of the carrier (or tank) solutions was as followe:

Soln A: 5 parts of 1 so-butyric acid +3 parts of $\mathrm{NH}_{4} \mathrm{OH}\left(\mathrm{aq}, 0.5 \mathrm{~mol}^{-\mathrm{L}^{-1}}\right)$.

Soln B: 7 parts of iso-propyl alcohol +1 part of conc. $\mathrm{NH}_{4} \mathrm{OH}+2$ parts of $\mathrm{H}_{2} \mathrm{O}$.

Soln C: 7 parts of $95 \%$ ethyl alcohol +3 parts of sodium acetate (aq, $1 \mathrm{~mol} \cdot \mathrm{L}^{-1}$ ).

Soln D: $\mathrm{H}_{2} \mathrm{O}$ adjusted to $\mathrm{pH} 10$ with $\mathrm{NH}_{4} \mathrm{OH}\left(\sim 1\right.$ drop of conc. $\mathrm{NH}_{4} \mathrm{OH}$ in $300 \mathrm{~mL} \mathrm{H}_{2} \mathrm{O}$ ).

Table 3. Data for the weasurements of the enthalpies of solution of various cytosine samples in water.

\begin{tabular}{|c|c|c|c|c|c|c|c|c|c|c|c|c|c|c|c|c|}
\hline \multirow{2}{*}{$\begin{array}{l}\text { Expt. } \\
\text { No. }\end{array}$} & \multirow{2}{*}{$\begin{array}{l}{ }^{a} \text { S.H. } \\
\text { cy1. }\end{array}$} & \multirow{2}{*}{$\begin{array}{l}\text { Sample } \\
\text { Mass } \\
\times 10^{5}\end{array}$} & \multirow{2}{*}{$\begin{array}{r}\mathrm{H}_{2} \mathrm{O} \\
\text { Mass } \\
-300 \mathrm{~g}\end{array}$} & \multirow{2}{*}{$\begin{array}{l}\text { Conc. } \\
\times 10^{6}\end{array}$} & \multirow{2}{*}{$\begin{array}{c}\text { Reaction } \\
\text { Period }\end{array}$} & \multirow{2}{*}{${ }^{\mathrm{T}}$ reaction } & \multirow{2}{*}{$\begin{array}{l}\text { Cal. } \\
\text { unc. } \\
\times 10^{2}\end{array}$} & $\begin{array}{c}\text { Electrical Energy } \\
\text { Equivalent } \\
-1730 \mathrm{~J} / \mathrm{K} \\
\end{array}$ & \multirow{2}{*}{$\begin{array}{c}-\Delta \mathrm{T}_{\text {react }} \\
\times 10^{5}\end{array}$} & \multirow{2}{*}{$\begin{array}{r}\text { EIt } \\
\times 10^{2} \\
\end{array}$} & \multirow{2}{*}{$\begin{array}{l}{ }_{\mathrm{q}_{\mathrm{vap}}} \\
\times 10^{2} \\
\mathrm{~J}\end{array}$} & \multirow{2}{*}{$\begin{array}{r}\begin{array}{c}-Q \\
\text { react } \\
\times 10^{2}\end{array} \\
\mathrm{~J}\end{array}$} & \multirow{2}{*}{$\begin{array}{r}-\mathrm{q}_{\mathrm{H}} \mathrm{H}_{2} \mathrm{O} \\
\times 10^{2} \\
J\end{array}$} & \multirow[t]{2}{*}{$\Delta \mathrm{H}_{\mathrm{m}}(\mathrm{T})$} & \multirow{2}{*}{$\begin{array}{c}\text { corr. to } \\
\mathrm{T}= \\
298.15 \mathrm{~K} \\
\mathrm{~J} / \mathrm{mol}\end{array}$} & \multirow{2}{*}{\begin{tabular}{|c}
$\frac{\Delta \mathrm{H}_{\mathrm{m}}}{(298.15 \mathrm{~K})}$ \\
$\mathrm{J} / \mathrm{mol}$
\end{tabular}} \\
\hline & & & & & & & & Initial / Final & & & & & & & & \\
\hline
\end{tabular}

\begin{tabular}{c|c|c|c|c|} 
Cyt 1: & \multicolumn{4}{|c|}{ Calbiochem Lot 840095} \\
\hline 897 & $\mathrm{~S}$ & 30817 & 2.459 & 9171 \\
898 & $\mathrm{~S}$ & 20727 & 2.454 & 6168 \\
899 & $\mathrm{~S}$ & 19840 & 2.459 & 5904 \\
900 & $\mathrm{~S}$ & 20219 & 2.444 & 6017 \\
901 & $\mathrm{~S}$ & 21219 & 2.424 & 6315 \\
902 & $\mathrm{~S}$ & 19977 & 2.459 & 5945 \\
\end{tabular}

\begin{tabular}{r|r|r|r|r}
157 & 298.170 & 85 & 8.06 & 7.11 \\
57 & 298.210 & 25 & 8.35 & 7.37 \\
27 & 298.205 & 13 & 8.75 & 7.80 \\
17 & 298.186 & 25 & 8.16 & 7.24 \\
18 & 298.180 & 8 & 8.11 & 7.61 \\
27 & 308.913 & 11 & 8.38 & 7.07
\end{tabular}

\begin{tabular}{l|}
3464 \\
2378 \\
2305 \\
2340 \\
2457 \\
2372
\end{tabular}

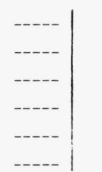

\begin{tabular}{l|l|}
2 & \\
2 & \\
2 & \\
2 & 40 \\
2 & 40
\end{tabular}

\begin{tabular}{l|r|r|r}
6016 & 13 & 195.63 & 21735 \\
4130 & 9 & 199.68 & 22184 \\
4005 & 8 & 202.29 & 22475 \\
4063 & 8 & 201.37 & 22373 \\
4268 & 9 & 201.56 & 22394 \\
4118 & 9 & 206.57 & 22950
\end{tabular}

Cyt 2: E-M Lot 1958515

\begin{tabular}{l|l|l|l|l|}
1223 & $\mathrm{~L}$ & 77313 & 2.384 & 23013 \\
1224 & $\mathrm{~L}$ & 56970 & 2.379 & 16958
\end{tabular}

Cyt 3: E-M Lot 4955544

\begin{tabular}{r|r|r|r|r}
1202 & L & 85496 & 2.414 & 25446 \\
1204 & L & 79298 & 2.389 & 23603 \\
1205 & S & 19336 & 2.424 & 5755 \\
1215 & S & 20866 & 2.384 & 6211
\end{tabular}

\begin{tabular}{l|l|l|l|l|}
17 & 298.210 & 6 & 5.16 & 4.29 \\
22 & 298.227 & 6 & 4.06 & 3.78
\end{tabular}

8699
6435

\begin{tabular}{l|l|l|}
88140 & 9 \\
88246 & 9
\end{tabular}

15081
11149

206.57122950

\begin{tabular}{lr|r}
- & 2 & $(21733)$ \\
- & 5 & 22179 \\
- & 4 & 22411 \\
- & 3 & 22370 \\
$-\quad 2$ & 22392 \\
$-\quad 822$ & 22128
\end{tabular}

Cyt 3a: Twice recrystallized from $\mathrm{H}_{2} \mathrm{O}$

\begin{tabular}{|l|l|l|l|l|l|l|l}
\hline 1206 & L & 82483 & 2.389 & 2455
\end{tabular}

\begin{tabular}{l:l|l|l|l|l|}
1207 & $\mathrm{~L}$ & 82159 & 2.409 & 24453
\end{tabular}

\begin{tabular}{l|l|l|l|l|}
1208 & $\mathrm{~S}$ & 20958 & 2.449 & 6237
\end{tabular}

\begin{tabular}{ll:l|l|l}
1210 & $\mathrm{~L}$ & 118576 & 2.389 & 35294
\end{tabular}

\begin{tabular}{l|l|l|l|l|}
1211 & L & 99953 & 2.409 & 29749 \\
\hline
\end{tabular}

\begin{tabular}{l|l|l|l|l|}
1212 & L & 50608 & 2.429 & 15062 \\
\hline
\end{tabular}

\begin{tabular}{l|l|l|l|l|}
1213 & $\mathrm{~S}$ & 10071 & 2.364 & 2998 \\
\hline
\end{tabular}

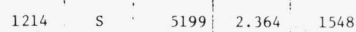

\begin{tabular}{ll|l|l|l|}
1217 & $\mathrm{~L}$ & 76644 & 2.404 & 22812
\end{tabular}

\begin{tabular}{ll|l|l|l}
1218 & $\mathrm{~L}$ & $51554^{\circ}$ & $2.439^{\circ}$ & 15342
\end{tabular}

\begin{tabular}{ll|lll}
1275 & $S$ & 19158 & 2.299 & 5704
\end{tabular}

\begin{tabular}{l|l|l|l|l|}
1276 & $S$ & 27799 & 2.294 & 8277
\end{tabular}

\begin{tabular}{l|l|l|l|l}
1277 & $S$ & 23027 & 2.264 & 6857
\end{tabular}

\begin{tabular}{l|l|l|l|l|}
1278 & $S$ & 9275 & 2.274 & 2896
\end{tabular}

\begin{tabular}{l|l|l|l|l|}
1289 & $\mathrm{~L}$ & 79552 & 2.344 & 23682 \\
\hline
\end{tabular}

\begin{tabular}{l|l|l|l|l|l|}
22 & 298.405 & 5 & 4.07 & 4.56 & 9666 \\
22 & 318.777 & 4 & 7.39 & 7.49 & 9441 \\
37 & 308.691 & 26 & 3.05 & 3.81 & 2508 \\
62 & 308.451 & 30 & 6.28 & 4.01 & 3003
\end{tabular}

\begin{tabular}{r|r|}
85995 & 9 \\
87730 & 25 \\
88136 & 4 \\
\hline--- & 4
\end{tabular}

\begin{tabular}{r|l|l|l}
16755 & 50 & 196.56 & 21839 \\
16378 & 49 & 207.16 & 23016 \\
4343 & 13 & 225.28 & 25029 \\
5207 & 16 & 250.29 & 27808
\end{tabular}

\begin{tabular}{r|r|r|r|r|r}
32 & 323.838 & 5 & 9.34 & 8.96 & 10345 \\
37 & 313.707 & 7 & 7.06 & 7.09 & 9791 \\
96 & 303.626 & 46 & 4.35 & 2.98 & 2539 \\
92 & 298.377 & 9 & 5.26 & 5.17 & 13618 \\
117 & 298.189 & 14 & 4.08 & 3.67 & 11571 \\
82 & 298.225 & 15 & 6.34 & 4.32 & 6015 \\
32 & 297.987 & 37 & 4.18 & 3.99 & 1269 \\
17 & 298.096 & 53 & 3.81 & 3.24 & 730 \\
50 & 321.222 & 13 & 9.61 & 9.14 & 9369 \\
27 & 303.612 & 9 & 4.92 & 4.91 & 6139 \\
42 & 298.100 & 42 & 4.06 & 1.85 & 2793 \\
132 & 298.093 & 51 & 1.78 & 0.74 & 3294 \\
127 & 298.104 & 70 & 2.00 & 0.99 & 2855 \\
37 & 298.109 & 43 & 1.57 & 1.03 & 1299 \\
42 & 303.190 & 7 & 5.24 & 4.47 & 9395 \\
42 & 308.496 & 6 & 4.97 & 4.87 & 9600
\end{tabular}

\begin{tabular}{r|r|r|}
87506 & 31 & 17960 \\
87440 & 19 & 16989 \\
87510 & 3 & 4399 \\
86763 & 8 & $c_{23617}$ \\
86682 & 8 & 20054 \\
86758 & 10 & 10428 \\
---- & 2 & 2199 \\
---- & 3 & 1263 \\
86677 & 26 & 16271 \\
88135 & 13 & 10637 \\
---- & 2 & 4838 \\
---- & 2 & 5701 \\
----- & 2 & 4941 \\
---- & 2 & 2247 \\
88741 & 12 & 16287 \\
89383 & 15 & 16640 \\
\hline
\end{tabular}

\begin{tabular}{l|l|l|}
-- & 217.74 & 24192 \\
-- & 206.78 & 22974 \\
-- & 209.90 & 23320 \\
-- & 199.17 & 22128 \\
-- & 200.80 & 22310 \\
-- & 206.05 & 22893 \\
-- & 218.35 & 24259 \\
-- & 242.93 & 26990 \\
-- & 212.29 & 23586 \\
-- & 206.33 & 22924 \\
-- & 252.53 & 28057 \\
-- & 205.08 & 22785 \\
-- & 211.57 & 23840 \\
-- & 231.05 & 25671 \\
-- & 204.73 & 22746 \\
-- & 207.24 & 23025
\end{tabular}

Cyt 3b: Twice recrystallized from $90 \%$ EtOH

1219 L I 79805 2.419| 23752 |

\begin{tabular}{|l|l|l|l|l|}
1220 & $\mathrm{~L}$ & 79342 & 2.364 & 23618 \\
\hline
\end{tabular}

Cyt 3d: Sublimed

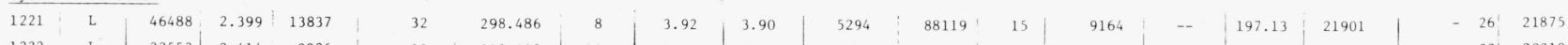

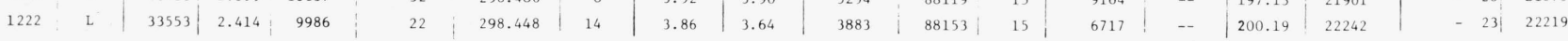

Cyt 4: E-M Lot 4958785

\begin{tabular}{l|l|l|l|l|l|l|l|l|l|}
\hline 1225 & $\mathrm{~L}$ & 63996 & 2.394 & 19048 & 27 & 298.220 & 8 & 4.03 & 3.92 \\
\hline
\end{tabular}

${ }^{\mathrm{a}}$ Two sizes of sample holder cylinders were used; the volumes are $\mathrm{S}=0.7 \mathrm{~mL}$ and $\mathrm{L}=3.0 \mathrm{~mL}$.

${ }^{b}$ The sublimed samples (Cyt 3d) were transferred to the sample holder in a glove box where the relative humidity (RH) was zero; all other samples were transferred in the laboratory atmosphere where $\mathrm{RH}=0.35+0.10$.

${ }^{c}$ This value includes a correction of $-0.05 \mathrm{~J}$ for the energy lost

vessel tenperature was less than that of the adiabatic shield 
made over the temperature range, $298 \mathrm{~K}$ to $324 \mathrm{~K}$, and the concentration range, 1.5 to $35 \mathrm{mmol} \cdot \mathrm{kg}^{-1}$. The endothermic reactions of cytosine in $\mathrm{H}_{2} \mathrm{O}$ were moderately rapid $(\sim 30$ $\min )$ at $298 \mathrm{~K}$ if the samples were loosely packed in the sample holder, however, some of the reactions required more than two hours. In most experiments a moderate stirring rate, 550 revolutions per min, was used.

Detailed descriptions of the samples and their analyses are given in section 2. All calorimetric samples were transferred to the sample holder in the laboratory atmosphere except the product of sublimation, Cyt 3d.

The general calorimetric procedures and methods of calculation have been described $[10,11]$. The electrical energy equivalents of the initial and final systems were measured in each experiment. In experiments where the heat absorbed during the endothermic reaction was expected to exceed 100 $\mathrm{J}$, precisely measured electrical energy was added during the reaction to prevent a decrease in the vessel temperature and a loss of adiabatic conditions; if less than $100 \mathrm{~J}$ of heat was absorbed, the stirring energy was sufficient to maintain the calorimeter temperature.

The calorimeter temperature was measured with a quartzoscillator thermometer system [1, 10]. The calibrations of this system and those of the standard cell and standard resistors used in electrical energy measurements were given previously [1]. The calorimetric experiments reported in this work were completed between December 1973 and April 1977. Uncertainties are given at the 95 percent confidence level except as noted.

The 1975 Table of Atomic Weights [12] was used to obtain molecular masses for this work as follows: cytosine, 111.103, and $\mathrm{H}_{2} \mathrm{O}$, 18.0152. Energy conversions were made according to the following relationship: 1 thermochemical calorie $=$ 4. 184 joules.

Data for 33 experiments in which enthalpies of solution of cytosine in water were measured are given in table 3 . The Experiment Number is a serial number for experiments with this calorimeter and indicates the chronological order of the experiments. S. H. Cyl. indicates the size of the sample holder cylinder used in each experiment. The Reaction Period is the elapsed time between initiating the reaction and the beginning of the rating period which follows the reaction. $T_{\text {reaction }}$ is the mean of the initial and final temperatures of reaction. The estimated calorimetric uncertainty for an experiment, Cal. Unc., is based on the duration of the reaction, the magnitude of the temperature change from the reaction, and the standard deviation of the slope of the rating period following the reaction (see [1] for details). The heat of the solution reaction, $Q_{\text {reaction, }}$ is given by the following equation: where the electrical energy equivalents (in $\mathrm{J} \cdot \mathrm{K}^{-1}$ ) of the initial and final systems are $\epsilon_{i}$ and $\epsilon_{f}$, the temperature change due to the solution reaction is $\Delta T_{\text {react }}$, and the heat of vaporization of water into the air space in the sample holder upon opening is $q_{\mathrm{vap}} . \Delta T_{\text {react }}=\Delta T_{-}$ $\operatorname{EIt}\left(\frac{\epsilon_{i}+\epsilon_{f}}{2}\right)^{-1}$ where $\Delta T$ (not given in table 3 ) is the net temperature change resulting from the endothermic solution reaction and the electrical energy added, EIt. $q_{\mathrm{vap}}=$ $\Delta H_{\mathrm{vap}}\left(V-\frac{s}{d}\right)(1-R H)$ where $\Delta H_{\mathrm{vap}}$ is the enthalpy of vaporization of water per unit volume at the mean temperature of reaction, $V$ is the internal volume of the sample holder, $s$ is the mass of sample, $d$ is the density of the sample, and $R H$ is the relative humidity of the atmosphere in which the sample was transferred to the sample holder (for the transfer in the dry box, $R H=0$; in the laboratory atmosphere, $R H=0.35 \pm 0.10)$. A correction, $q_{\mathrm{H}_{2} \mathrm{O}}=$ $Q_{\text {react }}$ (mass $\% \mathrm{H}_{2} \mathrm{O}$ ), is added to $Q_{\text {react }}$ for the water in the samples of Cyt 1, 2, 3, and 4 given at the end of section 2.1.1. The enthalpy of solution per gram at the temperature and concentration of the experiment, $\Delta H_{m}(T)=-\left(Q_{\text {react }}\right.$ $\left.+q_{\mathrm{H}_{2} \mathrm{O}}\right)$ (sample mass) ${ }^{-1}$.

The change in the enthalpy of solution with temperature, $\Delta C_{p}$, was obtained from the 10 experiments in table 3 in the concentration range, 22 to $26 \mathrm{mmol} \cdot \mathrm{kg}^{-1}$. The data for $T_{\text {reaction }}$ and $\Delta H_{m}(T)$ from these experiments are plotted in figure 1. (The point marked " $A$ " on the plot was for Expt. No. 1215 which was rejected and not included in table 3.)

A least squares fit of these 10 points to a linear equation gave a slope of $76.4 \mathrm{~J} \cdot \mathrm{mol}^{-1} \cdot \mathrm{K}^{-1}$; the standard error was $9.5 \mathrm{~J} \cdot \mathrm{mol}^{-1} \cdot \mathrm{K}^{-1}$. Thus in the range, $298 \mathrm{~K}<T<324 \mathrm{~K}$ $\Delta C_{p}=(76 \pm 21) \mathrm{J} \cdot \mathrm{mol}^{-1} \cdot \mathrm{K}^{-1}$. This was used to calculate the corrections to $T=298.15 \mathrm{~K}$ given in table 3 which were added to $\Delta H_{m}(T)$ to obtain the enthalpy of solution at the standard temperature, $\Delta H_{m}(298.15 \mathrm{~K})$.

A plot of these values given in the last column of table 3 versus the concentration of the final solutions is shown in figure 2 . The points representing various samples are distinguished by different symbols. The estimated calorimetric uncertainty for the experiment is equal to the radius of a circle (or a circle circumscribed by the other geometric figures). The straight lines shown were obtained from the fits of the data points by the method of least squares; the solid lines are from the fits of only the points for Cyt $3 \mathrm{~A}$ (open circles) with 7 points below and 9 points above $9 \mathrm{mmol} \cdot \mathrm{kg}^{-1}$, and the broken lines are from the fit of all 14 points below and 19 points above $9 \mathrm{mmol} \cdot \mathrm{kg}^{-1}$. The linear equations obtained are as follows (in $\mathrm{kJ} \cdot \mathrm{mol}^{-1}$ ):

Cyt $3 \mathrm{a},>9 \mathrm{mmol} \cdot \mathrm{kg}^{-1}$

$$
\begin{array}{cc}
\Delta H_{m}(298.15 \mathrm{~K}) & =22.91-0.027(C) \\
\pm 0.31 & \pm 0.43 \pm 0.018
\end{array}
$$




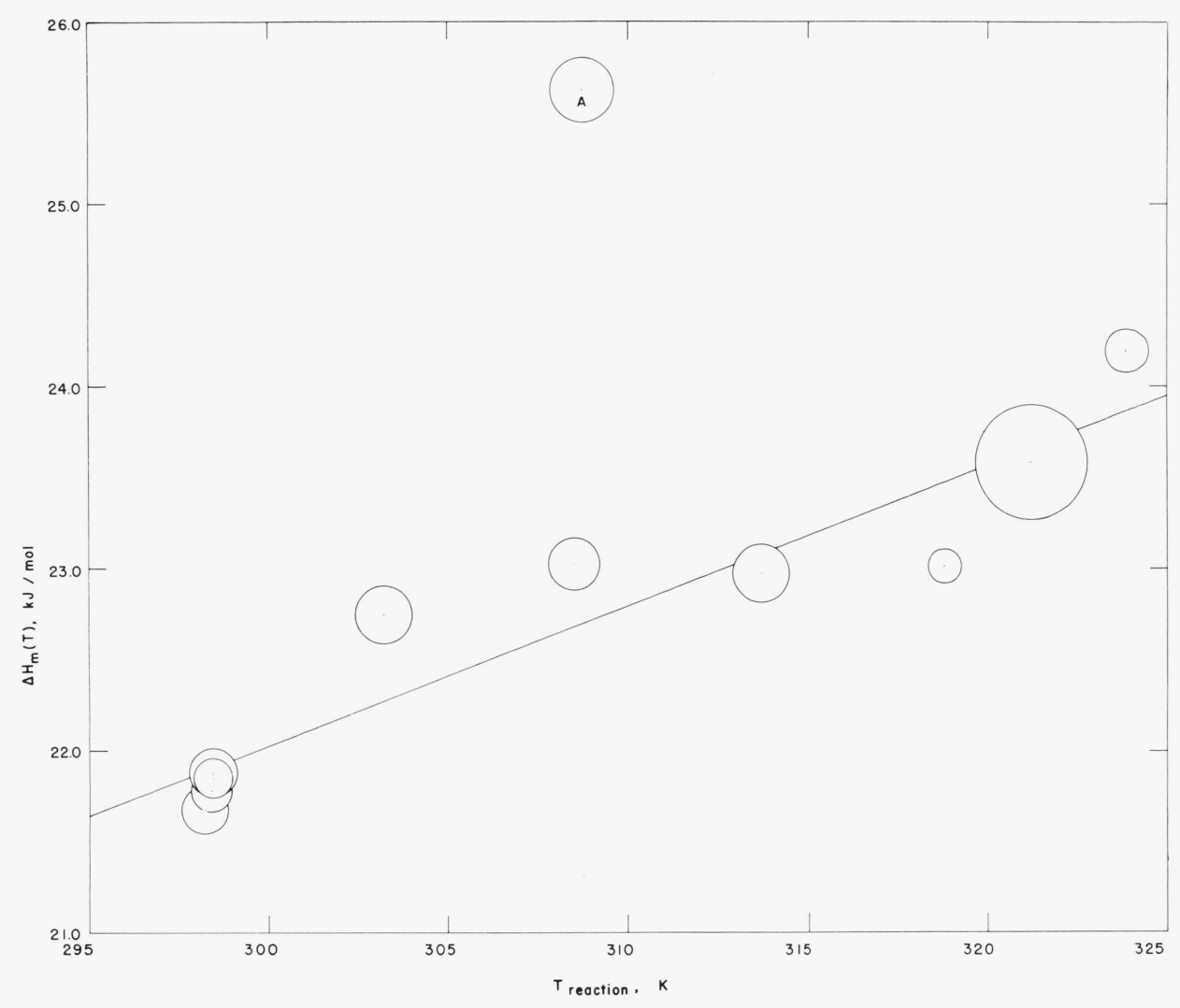

FIGURE 1. Plot showing the relationship between the mean temperature of reaction, $T_{\text {reaction, }}$ and the enthalpy of solution of cytosine in $\mathrm{H}_{2} \mathrm{O}$ at the concentration $(24 \pm 2) \mathrm{mmol} \cdot \mathrm{kg}^{-1}$.

The point marked " $\mathrm{A}$ " was omitted from the data for the least squares fit to obtain the straight line shown (slope $=\Delta C_{p}=76$ $\pm 21 \mathrm{~J} \cdot \mathrm{mol}^{-1} \cdot \mathrm{K}^{-1}$ ). The radius of a circle is equal to the estimated calorimetric uncertainty (see text).

All samples, $>9 \mathrm{mmol} \cdot \mathrm{kg}^{-1}$

$$
\begin{array}{cc}
\Delta H_{m}(298.15 \mathrm{~K}) & =22.13-0.005(C) \\
\pm 0.35 & \pm 0.28 \pm 0.013
\end{array}
$$

Cyt $3 \mathrm{a},<9 \mathrm{mmol} \cdot \mathrm{kg}^{-1}$

$$
\begin{array}{ccc}
\Delta H_{m}(298.15 \mathrm{~K}) & =27.2 & -0.46(C) \\
\pm 1.8 & \pm 1.7 & \pm 0.31
\end{array}
$$

All samples, $<9 \mathrm{mmol} \cdot \mathrm{kg}^{-1}$

$$
\begin{array}{ccc}
\Delta H_{m}(298.15 \mathrm{~K}) & =27.2 & -0.56(C) \\
\pm 1.9 & \pm 1.7 & \pm 0.29 .
\end{array}
$$

where $C$ is the concentration in $\mathrm{mmol} \cdot \mathrm{kg}^{-1}$ and the uncertainties are the standard deviations.

In figure 2 it can be seen that generally above $9 \mathrm{mmol} \cdot \mathrm{kg}^{-1}$ the values for Cyt 3a are larger than those for the other samples. This may indicate that impurities were removed in the recrystallization from $\mathrm{H}_{2} \mathrm{O}$. There is some evidence of inhomogeneity in the two low values at 23 and $24 \mathrm{mmol} \cdot \mathrm{kg}^{-1}$. There appears to be no significant difference between the values with Cyt 3 (filled circles) and those with sublimate, Cyt 3d (right half-filled circles). The spread of the data in figure 2 is larger than the estimated calorimetric uncertainties which suggests inhomogeneity in the samples.

The reason for the change in the slope of the lines near the concentration, $10 \mathrm{mmol} \cdot \mathrm{kg}^{-1}$, shown in figure 2 , is still not understood. The first supposition was that a protonation was completed at that concentration. However, Izatt et al [5] indicate $\mathrm{N}_{3}$ protonation of cytosine at $\mathrm{pK}=4.6$ and $\Delta H$ $(298.15 \mathrm{~K})=-5.14 \mathrm{kcal} \cdot \mathrm{mol}^{-1}$, an exothermic reaction which would be more complete as the concentration decreases, hence, the value for the endothermic enthalpy of solution should decrease as the concentration decreases; in figure 2, the opposite is observed. The possibility of the removal of the $\mathrm{N}_{1}$ proton from cytosine in aqueous solution $(\mathrm{pH}=6.4)$ is very unlikely since $\mathrm{pK}$ for the reaction is 12.15 [5]. The remaining possibility is an exothermic side reaction occurring at the lower concentrations.

Our previous experience with tris(hydroxymethyl)aminomethane gave evidence of an exothermic side reaction under some conditions in the presence of $\mathrm{CO}_{2}$ and $\mathrm{O}_{2}$ [11]. It was suspected, but not proven, that the amino group was involved 


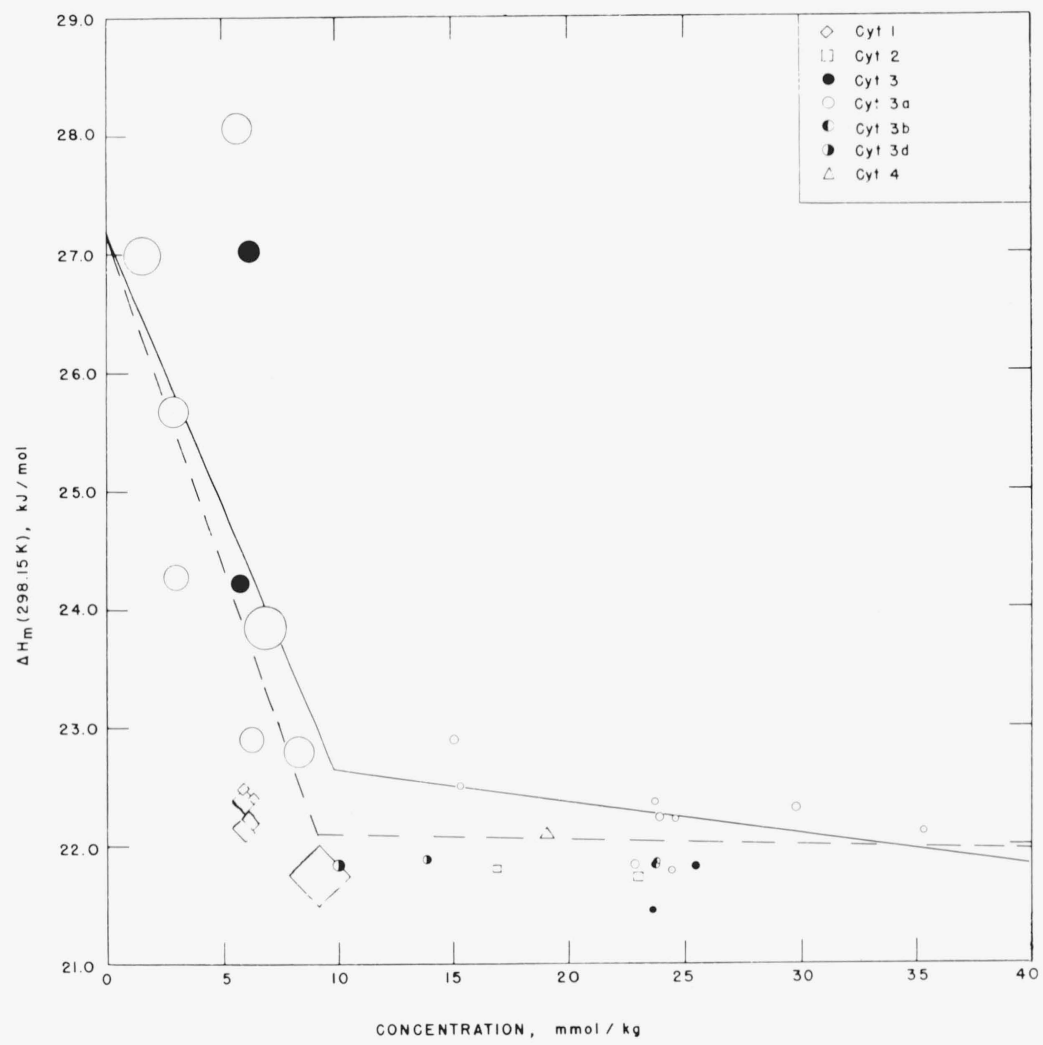

Figure 2. Plot showing the relationship of concentration and the enthalpy of solution of cytosine in $\mathrm{H}_{2} \mathrm{O}$ at $298.15 \mathrm{~K}$ using various samples distinguished by different symbols.

The solid lines result from a least squares fit of the data for only Cyt $3 \mathrm{a}$ above and below $9 \mathrm{mmol} \cdot \mathrm{kg}^{-1}$, and the dashed lines, for all points above and below $9 \mathrm{mmol} \cdot \mathrm{kg}^{-1}$. The estimated calorimetric uncertainty (see text) is equal to the radius of a circle (or a circle circumscribed by the other symbols).

in the side reaction. Cytosine also has an amino group which could participate in a similar reaction with the $\mathrm{CO}_{2}$ and $\mathrm{O}_{2}$ in equilibrium with the distilled $\mathrm{H}_{2} \mathrm{O}$ used for the calorimetric solution. The relatively small quantity of $\mathrm{CO}_{2}$ dissolved in the $\mathrm{H}_{2} \mathrm{O}$ could react with the cytosine until the solution was depleted of $\mathrm{CO}_{2}$, then at higher concentrations the side reaction would continue only with $\mathrm{CO}_{2}$ drawn through limited access from the atmosphere. This would account for the sharp increase in the enthalpy of solution as the concentration decreases. It is also interesting to note that plots comparable to figure 2 for thymine (in the preceding work) and for uracil (in the subsequent work) show no change in the enthalpy of solution with concentration. The structure of thymine and uracil are similar to that of cytosine except that they have an oxygen atom in place of the amino group (thymine also has a methyl group in place of a hydrogen). Thus, a side reaction with the amino group in cytosine is a possible but not a proven explanation for the change in slope at the lower concentrations as shown in figure 2 .

The increase in the enthalpy of solution of cytosine in $\mathrm{H}_{2} \mathrm{O}$ below $10 \mathrm{mmol} \cdot \mathrm{kg}^{-1}$ (fig. 2) must be the result of an unidentified side reaction rather than an ionization. The exothermic heat effect of this side reaction at infinite dilution is taken as the difference between the intercepts for equations (2) and (4), or $-5.1 \mathrm{~kJ} \cdot \mathrm{mol}^{-1}$ and the sum of the uncertainties is $2.0 \mathrm{~kJ} \cdot \mathrm{mol}^{-1}$. This uncertainty was doubled for assignment to the enthalpy of solution of cytosine in water at infinite dilution which was taken as the difference of the intercept in equation (2), $22.13 \mathrm{~kJ} \cdot \mathrm{mol}^{-1}$, and the heat of the side reaction, $-5.1 \mathrm{~kJ} \cdot \mathrm{mol}^{-1}$. Thus our best value is $\Delta H^{\circ}(\infty, 298.15 \mathrm{~K})=(27.2 \pm 4.0) \mathrm{kJ} \cdot \mathrm{mol}^{-1}$. The uncertainty is large enough to include reasonable uncertainties in the purity of the samples and other possible errors in the measurements.

\section{Discussion and Summary}

Larsen and Magid [6] reported the only direct measurement of the enthalpy of solution of cytosine in water prior to this work. No information about the purity of the sample or the concentrations at which their measurements were made was given in the paper or the supplemental material. The 20 percent discrepancy between their value, $(21.55 \pm 0.25)$ $\mathrm{kJ} \cdot \mathrm{mol}^{-1}$, and ours is probably due primarily to the apparent 
side reaction discussed at the end of the previous section. Our values above $9 \mathrm{mmol} \cdot \mathrm{kg}^{-1}$ agree with their value within about 2 percent.

Scruggs, Achter, and Ross [3] calculated the enthalpy of solution of cytosine in the saturated solution at $335 \mathrm{~K}, 32.09$ $\mathrm{kJ} \cdot \mathrm{mol}^{-1}$, from their solubility measurements; using our value for $\Delta C_{p}$, we obtain $31.17 \mathrm{~kJ} \cdot \mathrm{mol}^{-1}$ at $298 \mathrm{~K}$. With our equation (2) we calculate $\Delta H(298.15 \mathrm{~K})=21.75$ $\mathrm{kJ} \cdot \mathrm{mol}^{-1}$ at saturation, $76 \mathrm{mmol} \cdot \mathrm{kg}^{-1}$; then correcting for the side reaction, we obtain $26.85 \mathrm{~kJ} \cdot \mathrm{mol}^{-1}$ which is about 14 percent smaller than the value of Scruggs et al.

Our measurements with various samples of cytosine showed differences of several percent in the enthalpies of solution, and yet our analytical data could not explain these differences. Until measurements can be made with cytosine samples which are known to be of higher purity than ours, the value for the enthalpy of solution of cytosine in water at infinite dilution is taken as

$$
\Delta H^{\circ}(\infty, 298.15 \mathrm{~K})=(27.2 \pm 4.0) \mathrm{kJ} \cdot \mathrm{mol}^{-1} .
$$

The change in the heat capacity of the reaction with temperature at $(24 \pm 2) \mathrm{mmol} \cdot \mathrm{kg}^{-1}$ is
$\Delta C_{p}=(76 \pm 21) \mathrm{J} \cdot \mathrm{mol}^{-1} \cdot \mathrm{K}^{-1}$, $298 \mathrm{~K}<T<324 \mathrm{~K}$.

Because of the side reaction this may not apply to low concentrations.

Other useful thermodynamic data may be derived from these values. Scruggs, et al. [3] measured the solubility of cytosine at $277.8 \mathrm{~K}$ and at $309.8 \mathrm{~K}$. Assuming linearity between these temperatures, we calculate $76 \mathrm{mmol} \cdot \mathrm{kg}^{-1}$ as the solubility at $298.15 \mathrm{~K}$; the estimated uncertainty is 5 percent. Then

$$
\Delta G^{\circ}(298.15 \mathrm{~K})=-R T \ln m=(6.4+0.3) \mathrm{kJ} \cdot \mathrm{mol}^{-1}
$$

and

$\Delta S^{\circ}(298.15 \mathrm{~K})=\frac{\Delta H^{\circ}-\Delta G^{\circ}}{T}=(70 \pm 14) \mathrm{J} \cdot \mathrm{mol}^{-1} \cdot \mathrm{K}^{-1}$.

The uncertainty for the entropy value is the sum of the uncertainties on $\Delta H^{\circ}$ and $\Delta G^{\circ}$ divided by $298 \mathrm{~K}$.

The density of cytosine was measured at approximately $295 \mathrm{~K}$ as $(1.44 \pm 0.08) \mathrm{g} \cdot \mathrm{mL}^{-1}$.

The author expresses her appreciation to R. L. Biltonen at the University of Virginia for providing heat capacity measurements of the cytosine samples and for his consultations during this work.

\section{References}

[1] Kilday, M. V., J. Res. Nat. Bur. Stand. (U.S.), 83, No. 4, 347-370 (July-August 1978).

[2] Kilday, M. V., J. Res. Nat. Bur. Stand. (U.S.), 83, No. 6, 529-537 (Nov.-Dec. 1978).

[3] Scruggs, R. L., Achter, E. K., and Ross, P. D., Biopolymers 11, 1961-1972 (1972).

[4] Nat. Bur. Stand. (U.S.) Spec. Publ. 330, 1977 edition, pg. 11, 41 pages (1977).

[5] Izatt, R. M., Christensen, J. J., and Rytting, J. H., Chem. Rev. 71 , 439-481 (1971).

[6] Larsen, J. W., and Magid, L. J., J. Phys. Chem. 78, 834-839(1974).
[7] Falk, M., Can. J. Chem. 43, 314-318 (1965).

[8] Committee on Specifications and Criteria for Biochemical Compounds, "Specifications and Criteria for Biochemical Compounds," Third Edition, National Academy of Sciences, Washington, D.C. (1972).

[9] Biltonen, R. L., Department of Pharmacology, University of Virginia School of Medicine, Charlottesville VA, private communication, July 1977.

[10] Prosen, E. J., and Kilday, M. V., J. Res. Nat. Bur. Stand. (U.S.) 77A, No. 2 (Phys. and Chem.), 179-203 (1973).

[11] Prosen, E. J., and Kilday, M. V., J. Res. Nat. Bur. Stand. (U.S.) 77A, No. 5 (Phys. and Chem.), 581-597 (1973).

[12] Commission on Atomic Weights, Pure and Applied Chem. 47, 75-95 (1976). 